\title{
Psychopathological Symptoms of Depression in Parkinson's Disease Compared to Major Depression
}

\author{
U. Merschdorfa \\ D. Berg ${ }^{b}$ I. Csotic \\ F. Fornadic \\ B. Merz ${ }^{b}$ \\ M. Naumann ${ }^{b}$ \\ G. Becker ${ }^{d}$ T. Supprian ${ }^{\mathrm{e}}$
}

Departments of aPsychiatry and ${ }^{b}$ Neurology, University of Würzburg; ${ }^{\circ}$ Gertrudis Hospital, Biskirchen;

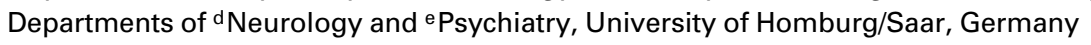

\section{Key Words}

Parkinson's disease - Major depression •

Psychopathology

\begin{abstract}
Parkinson's disease is frequently associated with depressive symptoms. When depression occurs at early stages and before the onset of characteristic motor symptoms of the disease, differential diagnosis of major depression may be difficult. Differences in psychopathological features of depression in Parkinson's disease and major depression have been reported by some authors. This study presents data of 49 patients with depression in Parkinson's disease and 38 patients with major depression. The severity of depressive symptoms was equivalent in both groups. Depressive features did not differ between the two groups with exception of affective flattening, delusional ideas and suicide attempts. In conclusion, this investigation gives support to the assumption of a common neurobiological origin of depression in Parkinson's disease and major depression.
\end{abstract}

Copyright $@ 2003$ S. Karger AG, Basel

\section{Introduction}

Many studies have shown a higher frequency and severity of depression in patients with Parkinson's disease (PD) than in other chronically disabling disorders [1-5]. In $\mathrm{PD}$, the incidence of depression is estimated to be about $40 \%[3,6,7]$. Studies focusing on the clinical features of depression in PD have reported a high frequency of anxiety symptoms [1], a low degree of guilt and selfreproach [8] and a relative lack of delusions and hallucinations [9]. The similarities between these symptoms and those of major depression (MD) are so strong, that distinguishing between MD and PD is sometimes difficult [9]. To date, a direct clinical comparison of depressive symptoms in depression of PD and MD has not been performed. However, comparisons between these groups have been performed for cognitive functions [10] and therapeutic strategies [11]. Here, we expand on these clinical studies by comparing psychopathological symptoms of depression in PD to those of MD. While some authors have described differences between depression in PD and MD, the basic hypothesis in our study was that the depressive syndromes are clinically comparable and share a common neurobiological origin. This assumption is supported by several neurobiological studies. Neuroimaging

Dr. U. Merschdorf

Department of Psychiatry, University of Würzburg

Füchsleinstrasse 15, DE-97080 Würzburg (Germany)

Tel. +49 93120176000, Fax +49 93120177550

E-Mail U_Merschdorf@klinik.uni-wuerzburg.de
Fax + 41613061234

E-Mail karger@karger.ch

www.karger.com

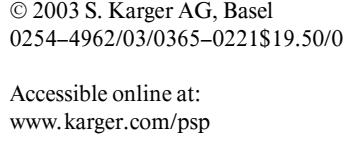


data, performed using transcranial sonography [12-15], magnetic-resonance imaging [15] and positron emission tomography [16], have indicated similarities of brain pathology in PD and MD. In addition, genetic association studies [17-20] and biochemical studies [21-24] of the basal limbic system suggest similar changes. We asked whether clinical findings are also similar in PD with depression and MD according to the overlapping neurobiological findings. The underlying concept is based on the assumption of basal limbic system alterations in MD as well as in depression in PD.

\section{Methods}

\section{Subjects}

Forty-nine patients with depression and PD (mean age $64 \pm 8$ years, 31 female, 18 male) and 38 patients with MD (mean age $60 \pm$ 16 years, 24 female, 14 male) were examined. There were no significant differences in age or gender between the groups.

Patients with PD and depression and patients with MD were recruited from two neurological hospitals (Würzburg and Biskirchen) and two psychiatric hospitals (Würzburg and Homburg/Saar). All patients with MD fulfilled the diagnostic criteria according to the Diagnostic and Statistical Manual of Mental Disorders (DSM-IV) [25]. Only inpatients were included in the study. Patients were initially screened for their willingness to participate in the psychiatric interview and were included after clinical stabilization and partial remission. Patients with a history of relevant substance abuse, significant head trauma, inflammatory or neoplastic central nervous system disorder, severe somatic disorder (e.g. carcinoma, instable cardiac disease) or dementia (Mini-Mental-State Examination score $<25)$ were excluded. At the time of examination, 2 of the MD patients and 5 of the PD patients were almost completely remitted. PD patients were not examined in 'off' phases. All patients included in the PD group fulfilled the British PD Brain Bank criteria [26] and the diagnostic criteria of an 'affective disorder in concomitant medical disorder' (DSM-IV: 293.83). All PD patients were submitted to a thorough neurological investigation including the Unified Parkinson's Disease Rating Scale (UPDRS) [27]. The severity of PD was classified according to Hoehn and Yahr (1967).

\section{Psychiatric Assessment}

After giving informed consent according to the Declaration of Helsinki, patients with either MD or depression and PD were interviewed by one of the two psychiatrists who investigated the patients of both groups. The psychiatric examination comprised a detailed semistructured interview based partly on the diagnostic criteria of DSM-IV. To exclude significant differences in the actual depressive state between the two patient groups, the following instruments and self-assessment rating scales were applied: Hamilton Rating Scale for Depression (HAMD) [28, 29], Beck Depression Inventory (BDI) [30-32], Befindlichkeits-Skala (Bf-S) [33], Brief Psychiatric Rating Scale (BPRS) [34], Clinical Global Impression Scale (CGI) [35], Snaith-Hamilton Pleasure Scale, German Version (SHAPS-D) [36].

The semistructured interview assessed the following central depressive symptoms: depressed mood, anxiety, anhedonia, hopeless-
Table 1. Frequency of occurrence of depressive symptoms in patients with depression and PD (PD) and with major depression (MD) according to the semistructured interview in percent of the whole group interviewed (n.s. $=$ not significant)

\begin{tabular}{lrrl}
\hline Symptom & PD, $\%$ & MD, $\%$ & U-test \\
\hline Depressed mood & 100 & 100 & n.s. \\
Anxiety & 73 & 76 & n.s. \\
Anhedonia & 94 & 92 & n.s. \\
Hopelessness & 88 & 84 & n.s. \\
Loss of energy & 100 & 100 & n.s. \\
Loss of drive & 86 & 95 & n.s. \\
Feelings of guilt & 51 & 55 & n.s. \\
Worthlessness & 59 & 58 & n.s. \\
Formal thought disorders & 86 & 79 & n.s. \\
Suicidal thoughts & 76 & 76 & n.s. \\
Irritability & 39 & 16 & n.s. \\
Inner restlessness & 73 & 50 & n.s. \\
Affective flattening & 39 & 76 & $\mathrm{p}<0.003$ \\
Delusions & 2 & 47 & $\mathrm{p}<0.001$ \\
Suicide attempts & 4 & 42 & $\mathrm{p}<0.001$ \\
\hline
\end{tabular}

ness, affectiveflattening, irritability, loss of interest, loss of energy, loss of drive, formal thought disorders, inner restlessness, delusions, feelings of guilt, feelings of worthlessness, suicidal thoughts and suicide attempts. To obtain the complete history of depression for each patient, patients were asked to report on the current as well as on previous depressive phases. The severity of depressive symptoms were graded on a 5-point scale by the two psychiatrists and assessed as being absent or existing in a relevant dimension.

\section{Statistical Evaluation}

Descriptive statistics are given as mean \pm SD. Inter-group comparison was performed using the Mann-Whitney U-test. Sequential adjustment according to Bonferroni was performed on the data given in table 1 because of multiple testing. Differences were assumed to be significant for $\mathrm{p}$ values $<0.05$.

\section{Results}

The characteristics of PD patients were as follows: the mean duration of PD was $8.5 \pm 5.7$ years. 27 patients showed a hypokinetic/rigid type and 22 an equivalent type of PD. No depressive PD patients had a tremor type of PD. According to Hoehn and Yahr, 18 patients were classified as grade II, 10 as grade II-III, 18 as grade III, and 3 as grade IV. Mean UPDRS scores were $5.2 \pm 2.2$ for part I (neuropsychological functions), $14.0 \pm 6.6$ for part II (activities of daily living), $32.2 \pm 8.9$ for part III (motor examination) and $3.7 \pm 3.4$ for part IV (complications of therapy). $54 \%$ of the PD patients suffered from 
depressive symptoms more than 1 year before the diagnosis of PD, $48 \%$ of the PD patients described an association between the severity of motor function and depressive symptoms during the day.

All PD patients received optimized medical treatment for the parkinsonian symptoms. Also, 9 PD patients were on antipsychotic drugs due to transient psychotic episodes. Because of delusional symptoms, $6 \mathrm{MD}$ patients received low-dose neuroleptic medication. Most patients ( 31 of 49 with PD and 36 of 38 with MD) were treated with antidepressant medication at the time of investigation. The antidepressive medication is summarized in tables 2 and 3 .

Comparison of depressive symptoms, as assessed by the different instruments, showed no difference between the groups concerning the current state of mood (table 4). However, the semistructured interviews, which assessed both the current and past symptoms of mood, did show differences in the frequency of occurrence of symptoms: More patients with PD described symptoms of irritability and inner restlessness than patients with MD. Significantly more patients with MD exhibited affective flattening, delusions and suicide attempts (table 1). Only 2 PD patients had a history of suicide attempts; both showed some atypical traits. One patient attempted suicide after an ischemic stroke. However, the depressive disorder had occurred before the ischemic event. The other patient suffered from depressive episodes accompanied by a suicide attempt several decades before PD was diagnosed. PD patients usually do not describe the typical 'endogenous' signs of MD, such as cyclic variation during the day and distinct episodes of several weeks or months. Instead, they describe a variation of depression severity that correlates with motor function.

However, there are many similarities. In this study, no difference in the occurrence of depressed mood, anxiety, anhedonia, hopelessness, loss of energy and drive, feelings of guilt and worthlessness, formal thought disorders (circling of thoughts), and suicidal thoughts was observed.

\section{Discussion}

As shown in many studies, depression frequently accompanies PD, but obviously, it does not occur equally in all types of PD. Depression seems to occur in PD patients suffering either from the hypokinetic/rigid type or from the hypokinetic/rigid type with tremor, but is less common in patients suffering predominantly from tremor. This is in line with previous reports $[37,38]$. These find-

Depression in Parkinson's Disease and

Major Depression
Table 2. Antidepressive medication of patients with major depression. A combination of two antidepressant drugs was given to 6 patients, 1 of whom received a combination of three antidepressant drugs

\begin{tabular}{lclc}
\hline Drug & $\begin{array}{l}\text { Patients } \\
\text { treated }\end{array}$ & $\begin{array}{l}\text { Dose range } \\
\mathrm{mg}\end{array}$ & $\begin{array}{l}\text { Mean dose } \\
\mathrm{mg}\end{array}$ \\
\hline Amitriptyline & 7 & $50-250$ & 128 \\
Doxepine & 5 & $80-225$ & 156 \\
Clomipramine & 4 & $50-225$ & 137 \\
Maprotiline & 3 & $75-125$ & 108 \\
Nortriptyline & 1 & 45 & 45 \\
Mirtazapine & 15 & $15-60$ & 42 \\
Venlafaxine & 7 & $75-225$ & 160 \\
Reboxetine & 1 & 10 & 10 \\
No antidepressant & 3 & - & - \\
\hline
\end{tabular}

Table 3. Antidepressive medication of Parkinson's patients with depression. A combination of two antidepressant drugs was given to 5 patients

\begin{tabular}{lccc}
\hline Drug & $\begin{array}{l}\text { Patients } \\
\text { treated }\end{array}$ & $\begin{array}{l}\text { Dose range } \\
\mathrm{mg}\end{array}$ & $\begin{array}{l}\text { Mean dose } \\
\mathrm{mg}\end{array}$ \\
\hline Amitriptyline & 11 & $10-150$ & 65 \\
Clomipramine & 4 & $37.5-75$ & 53 \\
Doxepine & 3 & $75-100$ & 91 \\
Maprotiline & 2 & $50-150$ & 100 \\
Fluoxetine & 1 & 40 & 40 \\
Citalopram & 2 & $10-20$ & 15 \\
Sertraline & 3 & 50 & 50 \\
Fluvoxamine & 2 & 100 & 100 \\
Mirtazapine & 3 & $30-45$ & 35 \\
Venlafaxine & 2 & $37.5-75$ & 56 \\
Hypericum extracts & 3 & - & - \\
No antidepressant & 18 & - & - \\
\hline
\end{tabular}

Table 4. Mean and standard deviation of rating scales in PD and depression and MD

\begin{tabular}{lccc}
\hline Scale & $\begin{array}{l}\text { PD and } \\
\text { depression }\end{array}$ & MD & U-test \\
\hline HAMD & $17.7 \pm 7.2$ & $18.3 \pm 7.6$ & $\mathrm{p}=0.7$ \\
BDI & $18.7 \pm 9.3$ & $17.2 \pm 11.1$ & $\mathrm{p}=0.2$ \\
Bf-S & $29.1 \pm 11.0$ & $30.3 \pm 14.6$ & $\mathrm{p}=0.4$ \\
BPRS & $42.3 \pm 6.8$ & $39.5 \pm 7.4$ & $\mathrm{p}=0.2$ \\
CGI & $3.9 \pm 1.1$ & $4.2 \pm 1.3$ & $\mathrm{p}=0.3$ \\
SHAPS-D & $2.3 \pm 2.3$ & $3.0 \pm 2.9$ & $\mathrm{p}=0.4$ \\
\hline
\end{tabular}

Psychopathology 2003;36:221-225 
ings support the hypothesis that depressive symptoms in PD may not merely represent a reaction to disability, but that MD and depression in PD might share a common pathology. The striking similarities of depressive symptomatology between depressive PD and MD patients support this hypothesis. Both patient groups in this study were representative clinical cohorts. With regard to the mean scores of the rating instruments, the two groups seemed to be comparable in depression severity. Nevertheless, severity of depression exhibited considerable variability within each sample. In fact, mean scores of the rating instruments indicate a wide range of depression severity. This variability may limit the conclusions which can be drawn from this investigation. It might be suggested to perform additional studies on psychopathological features in MD and PD patients with a more homogenous range of depression severity.

A close similarity of symptoms between the two groups according to the semistructured interview, relating to past and present depressive pathology, was found. Similarities in clinical symptoms correspond to the overlapping neurobiological findings of both entities [39-42]. We did not observe the reduced degree of guilt and self-reproach and increased frequency of anxiety symptoms in PD patients that was noted in other studies [1, 8, 43, 44]. However, in these studies the two disorders were not directly compared. In our study, only symptoms of irritability and inner restlessness seemed slightly more prominent in PD patients, but this did not reach statistical significance. These increases might be due to the impairment of movement initiation and performance, and the subsequent involvement of the dopaminergic system. A disturbed dopaminergic system could also be a reason for the association of motor function and depressive symptoms during the day in PD patients. Consistent with previous reports, we found that many patients suffer first from depressive episodes before the clinical manifestation of
PD [45]. At this stage, no clinical signs indicate that the affected patient will eventually develop PD; therefore an 'endogenous' type of depression is often suspected.

A statistically significant decrease was found only in affective flattening, delusional ideas and suicide attempts in PD patients as compared to MD patients. This confirms a previous report that depressive patients with PD have a lower frequency of delusions [9]. It has also been noticed that in spite of a high frequency of suicidal ideation, depressive PD patients rarely perform suicide [3, 46]. The reason for these important differences is not yet understood. It may be related to differences in severity of depression. Neither affective flattening, delusional ideas, nor suicide attempts are specific depressive features and the observed difference between the two groups in this regard seems to be of little relevance.

In conclusion, psychopathological features of depression in patients with MD and depressed PD patients were found to be quite similar. The similarities in psychopathological symptomatology as demonstrated in this study as well as the parallels in biochemical, genetic, histological and neuroimaging findings implicate a common pathogenetic basis of MD and depression in PD. The difference in some aspects of symptomatology otherwise suggests that there might be some additional pathogenetic factors accounting for the characteristics of both groups. The present study gives support to the hypothesis that depression in PD is not a distinct subtype of depressive disorders. The overlapping psychopathological features are in line with a common neurobiological origin of depression in PD and MD.

\section{Acknowledgement}

This study was supported by the German Kompetenznetz Parkinson, Förderkennzeichen 01GI020I.

\section{References}

1 Schiffer RB, Kurlan R, Rubin A, Boer S: Evidence for atypical depression in Parkinson's disease. Am J Psychiatry 1988;145:10201022.

2 Ehmann TS, Beninger RJ, Gawel MJ, Riopelle RJ: Depressive symptoms in Parkinson's disease: A comparison with disabled control subjects. J Geriatr Psychiatry Neurol 1990;3:3-9.

3 Cummings JL: Depression in Parkinson's disease: A review. Am J Psychiatry 1992;149: 443-454.
4 Menza MA, Robertson-Hoffman DE, Bonapace AS: Parkinson's disease and anxiety. Biol Psychiatry 1993;34:465-470.

5 Tandberg E, Larsen JP, Aarsland D, Cummings JL: The occurrence of depression in Parkinson's disease. Arch Neurol 1996;53:175179 .

6 Stefanova N, Seppi K, Scherfler C, Puschban Z, Wenning GK: Depression in $\alpha$-synucleinopathies: Prevalence, pathophysiology and treatment. J Neural Transm 2000;60:335-343.
7 Slaughter JR, Slaughter KA, Nichols D, Holmes SE, Martens MP: Prevalence, clinical manifestation, etiology and treatment of depression in Parkinson's disease. J Neuropsychiatry Clin Neurosci 2001;13:187-196.

8 Gotham AM, Brown RG, Marsden CD: Depression in Parkinson's disease: A quantitative and qualitative analysis. J Neurol Neurosurg Psychiatry 1986;49:381-389. 
9 Brown RG, MacCarthy B: Psychiatric morbidity in patients with Parkinson's disease. Psychol Med 1990;20:77-87.

10 Kuzis G, Sabe L, Tiberti C, Leiguarda R, Starkstein SE: Cognitive function in major depression and Parkinson disease. Arch Neurol 1997; 54:982-986.

11 Cantello R, Aguggia M, Gilli M, Delsedime M, Chiardo Dutin I, Ricco A, Mutani R: Major depression in Parkinson's disease and the mood response to intravenous methylphenidate: Possible role of the 'hedonic' dopamine synapse. J Neurol Neurosurg Psychiatry 1989 52:724-731.

12 Becker G, Struck U, Bogdahn U, Becker T: Echogenicity of the brainstem raphe in patients with major depression. Psychiatry Res 1994; 55:75-84.

13 Becker G, Becker T, Struck M, Lindner A, Burzer K, Retz W, Bogdahn U, Beckmann H: Reduced echogenicity of brainstem raphe specific to unipolar depression: A transcranial color-coded real-time sonography study. Biol Psychiatry $1995 ; 38: 180-184$.

14 Becker T, Becker G, Seufert J, Hofmann E, Lange KW, Naumann M, Lindner A, Reichmann H, Riederer P, Beckman H, Reiners K: Parkinson's disease and depression: Evidence for an alteration of the basal limbic system detected by transcranial sonography. J Neurol Neurosurg Psychiatry 1997;63:590-596.

15 Berg D, Supprian T, Hofmann E, Zeiler B, Jäger A, Lange KW, Reiners K, Becker T, Becker G: Depression in Parkinson's disease: Brainstem midline alteration on transcranial sonography and magnetic resonance imaging. J Neurol 1999;246:1186-1193.

16 Ring HA, Bench CJ, Trimble MR, Brooks DJ, Frackowiak RS, Dolan RJ: Depression in Parkinson's disease - A positron emission study. Br J Psychiatry 1994;165:333-339.

17 Collier DA, Stöber G, Li T, Heils A, Catalano M, Di Bella D, Arranz MJ, Murray RM, Vallada HP, Bengel D, Muller CR, Roberts GW, Smeraldi E, Kirov G, Sham P, Lesch KP: A novel functional polymorphism within the promoter of the serotonin transporter gene: Possible role in susceptibility to affective disorders. Mol Psychiatry 1996;1:453-460.

18 Gutierrez B, Pintor L, Gasto C, Rosa A, Bertranpetit J, Vieta E, Fananas L: Variability in the serotonin transporter gene and increased risk for major depression with melancholia. Hum Genet 1998;103:319-322.

19 Lesch KP, Mössner R: Genetically driven variation in serotonin uptake: Is there a link to affective spectrum, neurodevelopmental and neurodegenerative disorders. Biol Psychiatry 1998;44:179-192.
20 Mössner R, Henneberg A, Schmitt A, Syagailo YV, Grässle M, Hennig T, Simantov R, Gerlach M, Riederer P, Lesch KP: Allelic variation of serotonin transporter expression is associated with depression in Parkinson's disease. Mol Psychiatry 2001;6:350-352.

21 Chia LG, Cheng LJ, Chuo LJ, Cheng FC, Cu JS: Studies of dementia, depression, electrophysiology and cerebrospinal fluid monoamine metabolites in patients with Parkinson's disease. J Neurol Sci 1995; 133:73-78.

22 Leonard BE: The role of noradrenalin in depression: A review. J Psychopharmacol 1997; 11:39-47.

23 Schildkraut JJ: Neuropharmacology of affective disorders. Annu Rev Psychopharmacol 1973; 13:427-454.

24 Goodwin FK, Post RM, Dunner DL, Gordon EK: Cerebrospinal fluid amine metabolites in affective illness. The probenecid technique. Am J Psychiatry 1973;130:73-79.

25 American Psychiatric Association: Diagnostic and Statistical Manual Of Mental Disorders, ed 4. Washington, APA, 1995.

26 Ward D, Gibb WR: Research criteria for Parkinson's disease; in Streifler MB, Korzyn AD, Melamed E, Youdim MBH (eds): Parkinson's Disease: Anatomy, Pathology and Therapy. Adv Neurol 1990;53:245-249

27 Fahn S, Elton RL and Members of the UPDRS Development Committee: Unified Parkinson's disease rating scale; in Fahn S, Marsden CD, Goldstein $\mathrm{M}$ et al (eds): Recent Developments in Parkinson's Disease. II. New York, Macmillan, 1987, pp 153-163.

28 Hamilton M: A rating scale for depression. J Neurol Neurosurg Psychiatry 1960;23:56-62.

29 Leentjens AF, Verhey FR, Lousberg R, Spitsbergen $\mathrm{H}$, Wilmink FW: The validity of the Hamilton and Montgomery-Asberg depression rating scales as screening and diagnostic tools for depression in Parkinson's disease. Int J Geriatr Psychiatry 2000;15:644-649.

30 Beck AT, Ward CJ, Mendelsohn M, Mock H, Erbaugh J: An inventory for measuring depression. Arch Gen Psychiatry 1961;4:561-571.

31 Richter P, Werner J, Heerlein A, Kraus A, Sauer H: On the validity of the Beck Depression Inventory. Psychopathology 1998;31:160168.

32 Leentjens AF, Verhey FR, Luijckx GJ, Troost $\mathrm{J}$ : The validity of the Beck Depression Inventory as a screening instrument for depression in patients with Parkinson's disease. Mov Disord 2000; 15:1221-1224.

33 Zerssen D, Köller DM: Die Befindlichkeitsskala. Manual. Weinheim, Beltz, 1976.
34 Overall JE, Hollister LE, Pichot P: Major psychiatric disorders: A four-dimensional model. Arch Gen Psychiatry 1967;16:146-151.

35 Collegium Internationale Psychiatriae Scalarum: Rating Scales for Psychiatry. Weinheim, Beltz, 1990.

36 Franz M, Lemke MR, Meyer T, Ulferts J, Puhl P, Snaith RP: Deutsche Version der SnaithHamilton Pleasure Scale. Fortschr Neurol Psychiatr 1998;66:407-413.

37 Starkstein SE, Mayberg HS, Leiguarda R, Preziosi TJ, Robinson RG: A prospective longitudinal study of depression, cognitive decline and physical impairments in patients with Parkinson's disease. J Neurol Neurosurg Psychiatry 1992;55:377-382.

38 Oertel WH, Höglinger GU, Caraceni T, Girotti F, Eichhorn T, Spottke AE, Krieg JC, Peowe W: Depression in Parkinson's disease. An update; in Calne D, Calne S (eds): Parkinson's Disease. Adv Neurol 2001;86:373-383.

39 Birkmayer W, Riederer P: Biological Aspects of Depression in Parkinson's Disease. Psychopathology 1986;19(suppl 2):58-61.

40 Baumann B, Danos P, Diekmann S, Bilau H, Gerecke N, Bernstein HG, Bogerts B: Postmortem analysis of noradrenergic and serotonergic brainstem systems in mood disorders. Eur Arch Psychiatry Clin Neurosci 1998;248(suppl 2):79.

41 Baumann B, Danos P, Krell D, Diekmann S, Wurthmann C, Bielau H, Bernstein HG, Bogerts B: Unipolar-bipolar dichotomy of mood disorders is supported by noradrenergic brainstem system morphology. J Affect Disord 1999; 54:217-224.

42 Becker G, Berg D, Lesch KP, Becker T: Basal limbic system alteration in major depression: A hypothesis supported by transcranial sonography and MRI findings. Int J Neuropsychopharmacol 2001;4:21-31.

43 Brown RG, MacCarthy B, Gotham AM, Der RJ, Marsden CD: Depression and disability in Parkinson's disease: A follow-up study of 132 cases. Psychol Med 1988;18:49-55.

44 Henderson R, Kurlan R, Kersun J, Como P. Preliminary examination of the comorbidity of anxiety and depression in Parkinson's disease. J Neuropsychiatry Clin Neurosci 1992;4:257264.

45 Starkstein SE, Preziosi TJ, Bolduc PL, Robinson RG: Depression in Parkinson's disease. J Nerv Ment Dis 1990;178:27-31.

46 Myslobodsky M, Lalonde FM, Hicks L: Are patients with Parkinson's disease suicidal? J Geriatr Psychiatry Neurol 2001;4:120-124. 